Palimpsesto Vol. 10, № 17 (enero-junio, 2020): 78-98

Universidad de Santiago de Chile, ISSN 0718-5898

Mauricio Antonio Tapia Segovia

Universidad de Santiago de Chile

mauricio.tapias@usach.cl

\title{
La revista Portal: su aporte a la conformación del campo cultural chileno y el debate en torno a "lo latinoamericano" 1965-1969*
}

\author{
The Portal Journal: its Contribution to the Conformation of the \\ Chilean Cultural Field and the Debate around "the Latin \\ American" 1965-1969
}

\begin{abstract}
Resumen
Los 60's fueron caldo de cultivo para diversas disputas en los campos de la cultura y la política. Ante esta latencia, diversos artistas e intelectuales generaron redes de difusión y promoción de la cultura, las letras y las artes; es así que las revistas culturales de la época conformaron un territorio de proposiciones y confrontaciones centradas en establecer el rol del artista frente a su época y la tensión entre arte y política. La revista Portal (1965-1969) y su propuesta articulada por Marina Latorre, Eduardo Bolt y Luis A. Mancilla, se presenta como central para la comprensión y estudio de una época cruzada por diversas narrativas, donde el concepto de lo latinoamericano gana centralidad.
\end{abstract}

Palabras claves: Revistas Culturales, Campo Político, Campo Cultural, Latinoamérica, Intelectuales.

\begin{abstract}
The 60's were a breeding ground for various disputes in the fields of culture and politics. Given this latency, various artists and intellectuals generated networks to disseminate and promote culture, literature and the arts; Thus, the cultural magazines of the time formed a territory of propositions and confrontations focused on establishing the role of the artist in front of his time and the tension between art and politics. Portal journal (1965-1969) and its proposal articulated by Marina Latorre, Eduardo Bolt and Luis A.

${ }^{*}$ Esta investigación forma parte de los primeros resultados arrojados por mi tesis de grado de Magister titulada "Aproximaciones al debate entre arte y política en Revistas Culturales chilenas en el periodo de influencia cubana 1959-1973", que se enmarca en el proyecto Fondecyt n11170554, a cargo del académico e investigador Dr. César Zamorano del Centro de Estudios Enzo Faletto perteneciente a la USACH; y fue presentada en el Seminario Permanente sobre Estudios de Intelectuales, Soportes y Redes Culturales realizado el día 20 de junio de 2019, Universidad de Valparaíso.
\end{abstract}


Mancilla, is presented as central to the understanding and study of an era crossed by different narratives, where the concept of Latin American gains centrality.

Keywords: Cultural journals, political field, cultural field, Latin America, intellectuals.

\section{Introducción}

Este artículo, forma parte de una investigación que aborda los diversos debates y posturas adoptadas por la intelectualidad artística y política chilena en torno a los procesos históricos, políticos y culturales irradiados en las décadas de los 60 y comienzo de los 70 reflejados y articulados en las revistas culturales de la época. Procesos donde toma centralidad y profundidad una discusión en torno al arte y la literatura latinoamericanos como instancias simbólicas de constitución de una identidad latinoamericana en debate y construcción. De esta manera, la investigación busca demostrar la existencia de nudos de discusión acerca de "lo latinoamericano" y sus representaciones en el campo de lo artístico-cultural presente en la revista cultural chilena Portal (1965-1969) ${ }^{1}{ }^{2}$.

Se plantea como hipótesis general, que en un contexto de transformaciones y definiciones como lo fue la década de los 60 , en las revistas culturales -como publicación colectiva- se disputó el concepto de lo latinoamericano desde ámbitos asociados al campo político y al campo cultural. Ante esto, este artículo buscará caracterizar los principales núcleos o redes artístico-culturales que participan de las discusiones en torno a lo latinoamericano identificados en las revistas culturales, analizando los principales debates presentes sobre la tensión entre arte y política en las mismas. Ahora bien, en términos metodológicos si bien pareciese que la investigación gravitara en torno a un tema conceptual, esta tiene que ver más con la valoración semiótica de orden cultural del ejercicio detrás de la conceptualización. Por lo tanto, se echará mano a una propuesta de análisis para el estudio de revistas culturales propuestas por Alexandra Pita González y María del Carmen Grillo (2015) que propone una lectura a tres niveles: material (el lugar de edición, formato, cantidad de páginas y diseño, la impresión, papel y encuadernación, lugar, cantidad de números y etapas, periodicidad, precio y venta, tirada y zona de difusión), inmaterial (que nos remite al grupo humano que hace la publicación y que se conforma en una red intelectual), e intermedia de la revista (la que participa de ambas dimensiones por las características de las variables a estudiar, y responde a los contenidos).

En otras palabras no busca solo iluminar el texto, sino que el contexto y el entramado humano e institucional que agencia tras la creación y circulación, así como también generar una panorámica del campo cultural de la década de los sesentas, espacio temporal que se ha visto de cierta manera eclipsado por la coyuntura política de los primeros años de la década de los setenta en términos de estudios sobre proyectos culturales.

Este artículo se enmarca en una investigación más amplia que abarca un periodo de catorce años (1959-1973), los que se vislumbran por autores como Claudia Gilman (2003), como prodigiosos. Pues establecen un periodo intenso donde la revolución cubana de cierta manera

${ }^{1}$ La tesis de Magister en la que se enmarca este artículo además hace revisión de las revistas: Árbol de Letras (196768), Cormorán (1969-1970), La Quinta Rueda (1972-1973).

${ }^{2}$ Esta periodicidad corresponde a la primera época de la Revista, conformada por 7 números. 
impulsó una militancia artística e intelectual, bajo la premisa de que se vivía un momento histórico para pensarse y actuar. Ahora bien, mientras ocurría esto a nivel internacional en la esfera latinoamericana y con una audiencia global sobre el fenómeno, en Chile desde años anteriores a la Unidad Popular se venía gestando un diálogo enfocado en la transformación social donde según César Zamorano "la literatura, el arte y la cultura en general fueron comprendidos como instancias decisivas en la construcción de una nueva sociedad y lugar privilegiado para recomponer una identidad nacional" (Zamorano, 2016, p.216), remontándose a la década de los sesenta "la discusión y proliferación en Chile de discursos tendientes a replantear el lugar de la cultura en los procesos revolucionarios" (Zamorano, 2016, p.217), controversias que encontraron en las revistas de la época el espacio para debatir la contingencia latinoamericana.

A nivel regional, el proceso cubano irradiaba hacia Latinoamérica diversas iniciativas que buscaron romper con el bloqueo diplomático que realizaron los gobiernos de la época, instancia donde Casa de las Américas (1960-) realizó una profunda labor de generación de lazos de apoyo con la revolución y la creación de una red artístico cultural continental. Los esfuerzos realizados desde 1962 por una apertura en clave latinoamericanista surtieron éxito, y ya desde 1964 esta institución se convirtió en "el lugar donde sacó patente de existencia la nueva novela latinoamericana" (Gilman, 2010, p.7), apuntalando así la idea de que "podía celebrarse una revolución que no se enfrentaría al arte y los artistas, como lo había hecho la de octubre de 1917" (Gilman, 2010, p.6). El año 1965 marcó un punto de inflexión en torno a la postura de Casa de las Américas en tanto, con el escenario global de enfrentamiento en Vietnam y otros movimientos revolucionarios en el mundo, se convirtió en el portavoz de las aspiraciones tercermundistas, tornándose en el periodo 1965-1973 en "la vidriera simultánea de la red latinoamericana de letrados y la exaltación de las revoluciones por venir, tomando como modelo la cubana" (Gilman, 2010, pp.14-15), cuestión que se volverá problemática en la órbita de 1971 con el bullado caso Padilla y la postura irrestricta de la revolución cubana sobre la supeditación del artista a la revolución (Fornet, 2014), incidente que "desató un fuerte rechazo internacional que llevó a la ruptura definitiva de un grupo de escritores e intelectuales con la Revolución". A pesar de lo anterior, la Revolución Cubana "continuó siendo un espacio de legitimidad ideológica indiscutido para la mayor parte de la intelectualidad que en Latinoamérica perseguía el modelo del socialismo como una salida social" (Marchesi, 2010, p.126), cuestión que no fue distinta en Chile. Pues en la órbita chilena, existe una convivencia entre artistas-intelectuales militantes y no militantes (que han sido descritos como más bien heterodoxos, pero comprometidos con los procesos) (Canto, 2012; Zamorano, 2016) los que participan de este compartiendo algunos espacios en publicaciones pero que plantean una subjetividad distinta.

\section{Los Intelectuales y las revistas en internacionalismo latinoamericano}

Así como lo hemos planteado y siguiendo a Claudia Gilman (2003), es necesario comprender nuestro periodo de estudio en un ámbito internacional como respuesta al internacionalismo de la época, periodo que por lo demás y como hemos indicado también se refrenda la ascendente importancia de la política como valor que funda y legitima las prácticas intelectuales. Por tanto, debemos recurrir a la figura del intelectual el cual "es ineludible para vincular política y cultura, dado que implica tanto una relación con la cultura como una posición en relación con el poder" (Gilman, 2003, p.15). Tal como indica Bourdieu, los intelectuales son 
objeto de una delegación de hecho, global y tácita, que produce representaciones del mundo, estructurándose en campos, donde dicho campo "no es un espacio neutro de relaciones interindividuales, sino que está estructurado como un sistema de relaciones en competencia y conflicto entre grupos situaciones en posiciones diversas, como un sistema de posiciones sociales a las que están asociadas posiciones intelectuales y artísticas" (Bourdieu, 2002, p.5). Este enfoque de campos supone un cruce disciplinar que brinda distintas herramientas para el desafío de la reconstrucción de esa articulación "a partir de las marcas que la conflictividad social imprime en determinadas trayectorias significativas. Todo lo cual resulta clave para descifrar los momentos productivos de una corriente o fenómeno estético-político" (Beigel, 2003, p.110).

La década de los sesenta fue prolífica en la producción artística y literaria en Latinoamérica, incluso alcanzando su institucionalización y emergencia como una literatura de alcances continentales y consagración global en la misma década, periodo donde alcanzó su pico máximo de visibilidad, contribuyendo a rearmar una nueva tradición literaria latinoamericana en lo que se conoció como el boom latinoamericano; en este sentido toma importancia el hecho de que "las élites culturales han sido actores importantes de la historia de América Latina" (Altamirano, 2010, p.9). Independiente de la variada situación y rol que jugaron los intelectuales en América Latina en las distintas realidades nacionales, en términos generales desde fines del siglo XIX, se pueden encontrar indicios de una suerte de profesionalización e independencia de una industria cultural, alcanzando el rol del intelectual a mediados de siglo una categorización socio-profesional e irreductible (Altamirano, 2010).

Siguiendo la teoría de campos, el intelectual no está solo. Podemos indicar que por regla general se conectan entre sí a través de instituciones, movimientos y también revistas, donde "su ocupación distintiva es producir y transmitir mensajes relativos a lo verdadero" (Altamirano, 2010, p.12). Para nuestro caso, el tránsito entre la década de los sesenta y setenta nos entrega un escenario donde existe una cada vez mayor interrelación entre el campo cultural y el político, pues el artista-intelectual al indicar "publiquemos una revista" quiere decir "hagamos política cultural, cortemos con el discurso el nudo de un debate estético o ideológico" (Sarlo, 1992, p.9), lo cual lo insertaba en las diversas pugnas de poder, legitimidad, y construcción de sentido de la época. Nuevamente Cuba se ve como un polo central para entender el proceso chileno, donde la figura del artista para la revolución encuentra su símil en el "trabajador de la cultura", en el cual "es posible identificar un interés por obrar una nueva división de lo sensible" (Canto, 2012, p.160). Concepto influido probablemente por el anti-intelectualismo que se apoderó de muchos artistas e intelectuales de la época, quiénes asumieron esta posición como símil al de "revolucionario" lo que reflejaría un radicalismo ideológico, y "el crecimiento del valor de la política y sus lógicas de eficacia e instrumentalización" (Gilman 2003, p.30). De todas maneras, cabe indicar que en este artículo se utiliza la categoría de artista-intelectual, ya que para la fecha y en las revistas que se analizan-, podemos encontrarnos principalmente con artistas literarios (o de otra índole) que se dedican a escribir textos de carácter político-cultural en las revistas y otro tipo de publicaciones. Por tanto se explicita que esta idea del artista-intelectual será entendida como una categoría cercana a la propuesta por Gramsci de "periodismo integral", que lo describe como aquel que "no sólo trata de satisfacer todas las necesidades (de cierta categoría) de su público sino que se esfuerza por crear y desarrollar estas necesidades y por ello de estimular, en cierto sentido, a su público y de aumentarlo progresivamente" (Gramsci, 2009, p.149); esto ya que no hay que ignorar el contexto político y los diversos nexos de esta índole que presentan variados intelectuales y artistas participantes de las revistas, los que representan proyectos históricos y sociales. 
Tal como hemos indicado a través de esta introducción, nuestro principal objeto de estudio para abordar las aproximaciones al concepto de lo latinoamericano y la tensión entre política y arte, será la revisión y análisis de revistas culturales chilenas producidas en el periodo 1959-1973, trabajando específicamente la revista Portal (1965-1969). Ocuparemos este soporte por diversos motivos, el primero de ellos es que las revistas como publicación de carácter colectivo, han sido descritas como puntos de encuentro de trayectorias individuales y proyectos colectivos (Beigel, 2003; Pluet-Despatin, 2014; Elizalde, 2008); los cuales así como aglutinan también excluyen, cumpliendo "un papel determinante en la conformación del campo cultural latinoamericano" (Beigel, 2003, p.108), llegando a propiciar "nuevas comunidades imaginarias en un sentido político" (Ehrlicher, 2014, p.6). Independiente de si se considera de vanguardia o no, en su sintaxis la revista "rinde un tributo al momento presente justamente porque su voluntad es intervenir para modificarlo" (Sarlo, 1992, p.10), funcionando como un laboratorio de ideas donde se proponen y experimentan propuestas ideológicas y estéticas diversas y algunas veces antagónicas. Este mensaje o discurso elaborado muchas veces excede el campo cultural y entra en la arena del campo político, pues en ocasiones las revistas se prestan como instrumentos culturales para desafíos públicos más amplios (Sarlo, 1992; Pluet-Despatin, 2014).

Podemos por tanto indicar que la revista político-cultural de la época es un soporte imprescindible para la reconstitución de las tensiones entre el campo político y cultural, así como repositorio de discusiones que nos pueden orientar hacia la reconstitución de las redes artísticointelectuales detrás de su producción, y una discusión específica sobre el concepto de lo latinoamericano, ya que entendemos que "considerar el estudio de la prensa, en especial de las revistas culturales, una vía esencial para estudiar los intelectuales y sus prácticas" (Pita, 2014, p.262). Sobre esta relación de la revista en la construcción en torno círculos de cultura, y al entender la revista como "una estructura esencial de sociabilidad" (Pita, 2014, p.265), es menester rescatar la discusión propuesta por Pita, que ilumina un debate realizado por Dosse (2002) que enfrenta la categoría de "Campo" de Bourdieu con la de "afinidad electiva" de Lowy (1997), prefiriendo esta última debido al ambiente de cooperación interna que se observa en las revistas. Por tanto, podemos plantear dos niveles: uno interno de la revista de afinidad electiva, $\mathrm{y}$ uno mayor de interacción social y competencia en los campos político y cultural.

El periodo de estudio muestra la configuración de una fuerte voluntad por debatir la idea de América Latina, proceso que fue influido por "ciertas coyunturas de orden histórico-político, matrices ideológicas y el peso de ciertas instituciones como partidos, gobiernos, instituciones culturales y hasta mercantiles" (Gilman, 2003, p.27). Búsqueda de un patrimonio común que más allá de negar los distintos componentes nacionales, buscó generar una superación de estos en el plano cultural. De esta manera, hacia 1970 la idea de un común espacio de identificación en América Latina "se extendía por el continente dando lugar al surgimiento de nuevos vínculos culturales [los que] respondían a una serie de ideales comunes que, en términos generales, podemos englobar bajo el ala de la "teoría de la dependencia"" (Marchesi, 2010, p.121). Ya lo indicaba Ángel Rama, al decir que "ser latinoamericano es una tarea histórica y social y supone la exigencia de no permitirnos el facilismo y mucho menos, el conformismo" (Rama, 1998, p.9), cuestión que comparte Berríos en su tesis de Magíster al indicar que "el arte latinoamericano, conceptualmente hablando, es un proyecto que va configurando su propio discurso" (Berríos, 2011, p.26) y que por lo demás "el problema de la identidad no es exclusivo de Latinoamérica, sino que es constituyente de todas aquellas regiones que producen arte pero que no se encuentran en el lugar hegemónico de tales relaciones, sino que lo hacen desde la periferia" (Berríos, 2011, p.25). Otros autores plantean una discusión de larga duración sobre lo latinoamericano, así Bravo 
siguiendo a Ardao, indica que "el término "América Latina" guarda una relación estrecha con el imperialismo desde que la expresión fue acuñada a partir de la invasión francesa a México en el siglo XIX", entendiéndolo en relación con políticas euro-norteamericanas de dominación imperial, aunque también vinculado "con el eje antiimperialista, articulado en redes contrahegemónicas donde escritores y artistas cumplieron un papel central" (Bravo, 2009). Por tanto, y para cerrar el tema nos identificaremos con la postura de Alexandra Pita quién comprende América Latina como "un mosaico de numerosos países que ocupan territorialmente una parte considerable del continente americano", importando más que su aspecto geográfico, la percepción del mismo y la construcción de este como "una comunidad imaginada" (Pita, 2016).

Pasando a otro tema, y para dar un ejemplo de estudios similares a este, que abordan las tensiones e interrelaciones entre política y cultura; Ana Longoni en Argentina estudiando el periodo 1959-1974 llega a la conclusión de la existencia de fases distintas de esta relación entre campos político y cultural. Donde "en la primera fase de la época, la vanguardia se percibe a sí misma como revolución [...] En la segunda, la vanguardia artística se concibe como parte de la vanguardia política, como actor implicado en el curso de la revolución", mientras que en la tercera fase "el anti intelectualismo dominante y el mandato de pasar a la política despojan de su sentido la defensa de la especificidad artística de la vanguardia. Es entonces cuando ser vanguardia deja de ser una posición valorada y la revolución (política, incluso militar) pasa a concebirse como la mayor obra de arte posible" (Longoni, 2004, pp.427-428). Pero el caso chileno carece de estudios recientes sobre las temáticas estudiadas, en términos generales para la década del sesenta, siendo la del setenta la que concentra la atención. Por tanto, existe un vacío historiográfico a llenar en torno a la participación de las revistas en la constitución del campo cultural y político de la década del sesenta; aunque pueden ayudar como base de un estudio de redes, el trabajo de Soledad Bianchi (1995).

Tomando en cuenta lo expuesto, en esta investigación buscaremos responder ¿quiénes son los artistas-intelectuales que dan vida a las Revista Portal (1965-1969)? ¿cuáles fueron las claves de las discusiones o proposiciones en torno a la idea de Latinoamérica presentes en esta revista? ¿cómo reaccionan la publicación frente a la figura de Cuba y Casa de Las Américas durante la temporalidad de tiraje?; y no menos importante ¿qué impactos se logran reflejar en la obra de estos artistas-intelectuales y sus discusiones, en torno a la construcción de la idea de Latinoamérica en un contexto de alta tensión entre los campos cultural y político?

\section{Portal}

La revista Portal (1965-1969) dirigida por Luis Alberto Mancilla y Marina Latorre, se publicó al alero de un emprendimiento cultural familiar establecido por Eduardo Bolt Vega y Latorre (quienes eran matrimonio) llamado Ediciones Bolt; comenzando la edición de su primera época en diciembre de $1965\left(n^{\circ} 1\right)$ y finalizando en mayo de $1969\left(n^{\circ} 7\right)^{3}$. En sus páginas se reproducen numerosos elementos conformantes del campo cultural y artístico de mediados de la década del sesenta, escribiendo en ella diversos literatos e intelectuales de la época. Centrando sus discusiones principalmente en torno a la cuestión de la literatura chilena y su posición

\footnotetext{
${ }^{3}$ La revista Portal contó con tres periodos, el nombrado representa la primera con 7 números editados entre 1965 y 1969. La revista cesó su publicación entre 1970 y 1975, para ser retomada en 1976 hasta 1984 con excepción de 1983 (segundo periodo); y finalmente se editó entre 1996 y 2010 alcanzando una totalidad de 39 números.
} 
respecto a producción latinoamericana, la postura del artista frente a la época, la emergencia sobre la construcción de una identidad latinoamericana y la tensión entre el arte y la política; cuestiones que se ven enriquecidas por una amplia panorámica que aborda diferentes iniciativas y escenas culturales provenientes de la música, el teatro, la danza, la pintura y las letras.

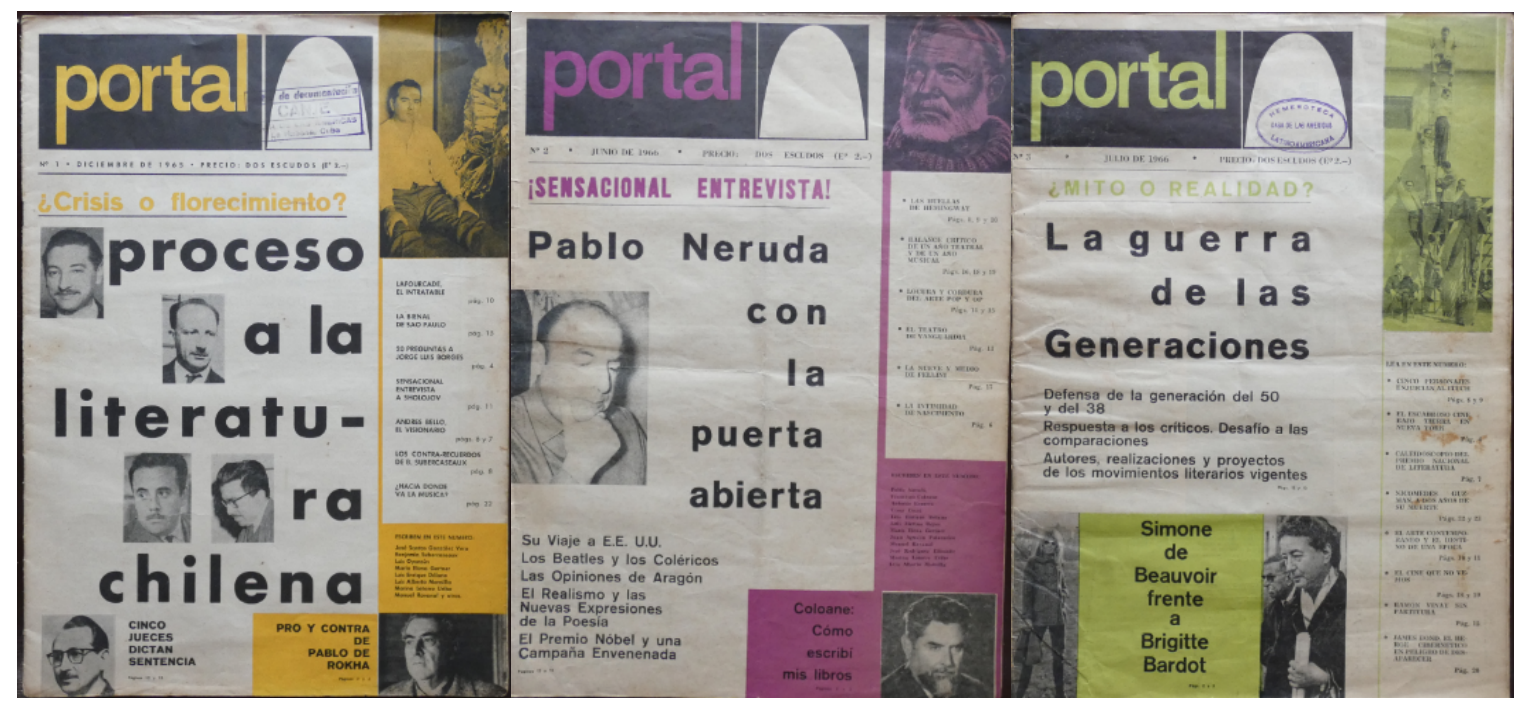

Imagen 1. Portada de los números 1, 2 y 3 de la revista Portal

Partiendo por la dimensión material, Portal tuvo sus oficinas de redacción en Santiago Centro, específicamente en Londres 92. La revista está compuesta en sus 7 números por 24 páginas. Además, incorpora diversas imágenes ya sean caricaturas o reproducciones de fotografías que acompañan generalmente los textos. Sobre el papel y la impresión, se realiza en su totalidad -y solo a excepción de la portada de cada número- en blanco y negro. Los colores utilizados en los primeros cinco números de la revista son: amarillo, violeta, verde, azul y naranja respectivamente; los cuales son eliminados de la portada en los números 6 y 7 . Sobre su publicación, esta es más bien dispersa en cuanto a que no se rige por una periodicidad mensual estricta, presentando así cierta frondosidad con tres números en 1966, pero por otro lado llegando a no publicarse el año 1968. Sobre el precio de la revista, esta comenzó costando 2 Escudos hasta el tercer número, desde el cuarto (noviembre de 1966) pasó a costar 3 Escudos, precio que para el número 7 se elevó a 5 Escudos; cuestión que más que representar un aumento real del precio de Portal, refleja la crudeza del fantasma de la inflación que azotó a Chile durante todo el siglo XX, pasando de convertirse el dólar de 3,96 Escudos en 1966 a 8,97 en 1969, reducción de dos y pico veces el valor cambio original, lo que se ve reflejado en el aumento proporcional del precio de la revista.

Sobre su venta, no se ha logrado rastrear un indicio claro de su venta en kioscos, aunque no hubiese sido raro pues su misión era de difusión cultual, lo que queda plasmado en su primera editorial donde se plantea que Portal:

desea satisfacer una necesidad de nuestra vida cultural. Pretende ser una revista accesible a cualquier lector que, de alguna manera, le interesen las manifestaciones de las letras, las artes plásticas, la música, el cine, el teatro, el ballet. No desea ser una 
publicación para los entendidos, de carácter académico, dirigida a una minoría erudita y exquisita. Creemos que existe una gran masa de gente sencilla, ávida de satisfacer en nuestro medio un órgano de prensa que traduzca sus requerimientos. Para ellos existe esta revista. (Portal $\left.\mathrm{n}^{\circ} 1, \mathrm{p} .5\right)$

Cada número es acompañado por invitaciones a suscribirse a la revista, e indicando los precios relativos a esto. Respecto a sus zonas de difusión estas fueron nacionales e internacionales, pues ya en la segunda aparición de Portal se publicita que se acepta canje con cualquier publicación cultural del país o del extranjero, pidiendo enviar la correspondencia al igual que con otros documentos a las oficinas de redacción en Londres 92 (Portal n², p.10). Hasta el momento hemos podido rastrear que su circulación habría llegado a diversos espacios internacionales como Casa de las Américas, y también por Alemania, Perú, y Argentina, así queda consignado en la editorial del número 5, la que expone que, a pesar de las desavenencias económicas, los objetivos de la revista se cumplen y el esfuerzo se ve compensado por la persistente gravitación nacional e internacional que ha tenido la corta etapa vivida [de la revista]. Es así como Humboldt (República Federal Alemana) reproduce nuestro artículo ¿Hacia dónde va la música? En Perú, El Comercio de Lima y La Crónica, en su suplemento dominical, transcriben la entrevista a Nicanor Parra. En Buenos Aires, La Prensa, comenta las características de Portal, y reimprime la crónica sobre Pablo Neruda. En Francia, Paris-Match, se preocupa de nuestra entrevista a Sholojov. (Portal n ${ }^{\circ}$, p.5)

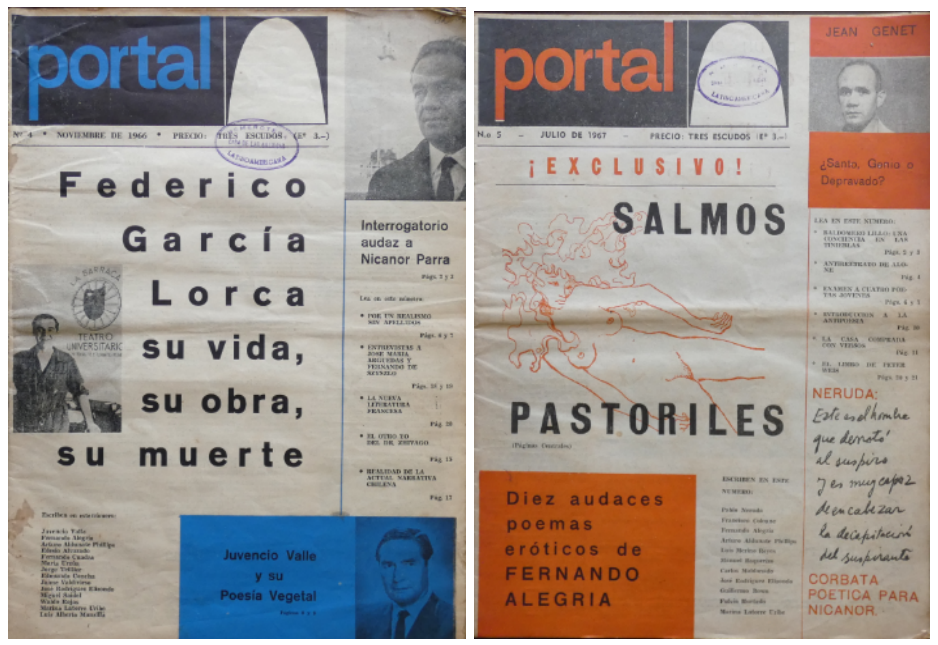

Imagen 2. Portadas de los números 4 y 5 de la revista Portal

En tanto la dimensión inmaterial, compuesta por la red humana que soporta la revista, fue mutando a través de sus 7 números. Es así como Luis Alberto Mansilla ${ }^{4}$ asume el rol de la

${ }^{4}$ Luis Alberto Mansilla (1930-2016) fue un periodista de cultura y militante comunista que participó en diferentes publicaciones y revistas. Además de su participación en Portal, dirigió la revista Vistazo, y colaboró fuertemente con El Siglo y Punto Final. Luego del Golpe cívico-militar de 1973, Mansilla vivió el exilio en la URSS, Francia, y la RDA. Desde el exilio participó activamente en la revista Araucaria de Chile, y tuvo la dirección del Boletín Exterior de la CUT. Al regreso del exilio participó en el Boletín y Cuadernos de la Fundación Neruda, además de colaborar en Punto Final y en LOM, editorial donde publicó los libros "Gente del siglo XX" (2010) y "Hoy es todavía, José Venturelli, una biografía" (2003). 
dirección entre los números 1 y 4, siendo reemplazado por Marina Latorre Uribe ${ }^{5}$ quién asume con el cargo de Directora Propietaria desde el número 5. La salida de Luis Alberto Mansilla se debió según lo expuesto en la revista a que este "ha pasado a dirigir la Revista Internacional Enfoque, de la Agencia Novosti. Esta importante función y sus labores de crítico del vespertino "Última Hora" y redactor de "El Siglo", han determinado su alejamiento de Portal, publicación en la que cumplió la difícil etapa de su iniciación" (Portal n 5 , p.5). En el número 5 se unió al Comité Editorial como Director Reemplazante Fulvio Hurtado Rojas, dejando el puesto vacante para el número 6; mientras que en el número 7 y final del periodo se integra Raúl Mellado ${ }^{6}$ como subdirector. Durante todos los números de Portal se nomina como Gerente de la revista a Eduardo Bolt Vega ${ }^{7}$, quién desde el número 4 además detenta el cargo de Representante Legal.

Respecto al ente impresor de Portal, esta se realiza durante el primer número en la Imprenta N. Mueller de Santiago; desde los números 2 al 4 en los Talleres de Arancibia Hnos. Mientras que el número 5 se imprimió en la Imprenta-Editorial Entrecerros, para finalmente en los últimos dos números asumir la edición, impresión (además de la propiedad que ya detentaba) Ediciones Bolt. Cabe agregar que en los números 3 y 4 aparece como encargada de diagramación Marina Latorre.

La revista tuvo entre sus colaboradores a diferentes artistas, críticos e intelectuales que participaron con textos y gráficos. Entre sus principales colaboradores (ordenados de mayor cantidad de aportes a menos ${ }^{8}$ ) podemos encontrar a: Marina Latorre Uribe (5), Luis Alberto Mansilla (4), José Rodríguez Elizondo (4), Fernando Alegría (3), Luis Merino Reyes (3), María Elena Gartner (3), Luis Oyarzún (2), Raúl Mellado (2), Pablo Neruda (2), Francisco Coloane (2), Arturo Aldunate Phillips (2), Juvencio Valle (2), Fulvio Hurtado Rojas (2), Carlos Maldonado

\footnotetext{
${ }^{5}$ Marina Latorre Uribe es profesora de Castellano y Periodista por la Universidad de Chile y Licenciada en Comunicación por la Universidad de Santiago. Además de participar como directora y dueña de Portal, Latorre fundó las revistas culturales Carta (1982-1984) y Diplomática; y ha colaborado en diversos medios escritos desde El Siglo hasta El Mercurio. Activa en el ámbito cultural y literario, a través de su vida ha ostentado cargos tales como el de Presidenta de la Corporación Socio Cultural Barrio San Francisco, Presidenta del Comité de Adelanto del Barrio París-Londres-San Francisco, Consejera de la Municipalidad de Santiago, entre otras distinciones entre las que resaltan los diversos reconocimientos que se le han hecho en la SECH. Ha publicado diversas obras entre las que destacan: "Galería Clausurada", cuentos, 1964, ediciones Bolt; "Soy una mujer", testimonio, 1973, ediciones Bolt; "El Regalo”, cuento, 1974, ediciones Bolt; "Fauna Austral”, poesía, 1977, ediciones Bolt; “¿Cuál es el Dios que pasa?, Novela, 1978, ediciones Nascimento; "Ventisquero", poesía, 1981, ediciones Bolt. Han prologado sus libros: María Luisa Bombal, Pablo Neruda, Francisco Coloane y Andrés Sabella.

${ }^{6}$ Raúl Mellado (1931-2004-5?) fue un poeta y periodista chileno. Fue director de la revista "Vistazo", director del suplemento cultural del diario "El siglo", redactor del diario "Central" de Chillán y Jefe del departamento de prensa de la radio de la ex Universidad Técnica del Estado hasta 1973. Autor de "Poemas" (1950), "La tierra colorada" (1958), Premio "Alerce" de la SECH siendo jurados Nicanor Parra, Juvencio Valle, y Luis Oyarzún; "Cuerdas de lluvia" (1978), "Verbo de la tierra" (1981), "Tren del sur y otros poemas" (1989), "Musas a la cacerola" (1994), y "Como si fuera un puente" (1999). Durante sus últimos años se desempeñó como Secretario Técnico de la Sociedad de Escritores de Chile, y director de la revista de poesía "La Hoja Verde", junto a su esposa Lavinia Lara, donde editó a cientos de vates de Chile y del mundo, en un esfuerzo por dar a conocer lo mejor de la producción poética de comienzos de siglo.

${ }^{7}$ Eduardo Bolt Vega fue el marido de Marina Latorre y dueño de diversos emprendimientos de carácter cultural. Además de contar con las Ediciones Bolt que editaban libros de poesía, literatura, y revistas como Portal o Carta; contaba con la Galería Bolt donde se presentaban diversas exposiciones de arte. También cuentan entre las iniciativas culturales la puesta en marcha de el DICAP (Discoteca del Cantar Popular) que grababa a Quilapayún, Inti-Illimani, Víctor Jara, a los Parra, y Patricio Mans. Junto a su esposa participaban de un círculo cultural que tenía entre otros exponentes a Jorge Teillier y Pablo Neruda.

${ }^{8}$ La cifra contenida entre paréntesis representa la cantidad de artículos publicados por cada colaborador
} 
(2), Alejandro Lipschütz (2), y Miguel Saidel (2). Existiendo además una extensa cantidad de aportes únicos a la revista donde otros 39 artistas e intelectuales escribieron en la publicación. Respecto a la colaboración en cuanto a gráficos estos fueron claramente menores, siendo principalmente la fotografía el recurso gráfico que junto a la publicidad acompañan los textos, apreciándose también algunas reproducciones de obras como el dibujo de Stravinski hecho por Piccaso reproducido en el primer número de Portal, así otros casos como una obra de Kandinsky también reproducida por nombrar alguno. De los casos que me parecen relacionados a colaboraciones gráficas, podemos encontrar en el número 2 y ligado a un recuento de los principales hitos del teatro de 1965, dos caricaturas: la de Pury Durante (actriz que participó en la laureada obra "La Mamma"), y una caricatura que recuerda al fallecido dramaturgo, crítico y periodista de la época Nathaniel Yáñez Silva.
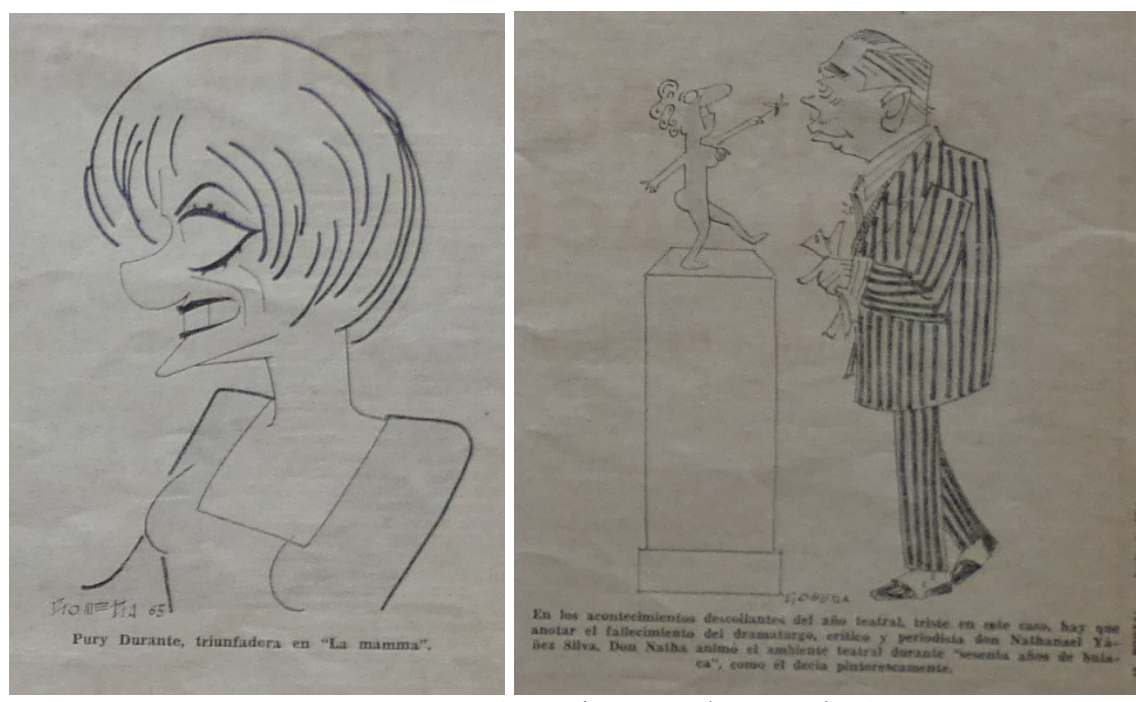

Imagen 3. Caricaturas de Portal n 2

Sobre la dimensión relacionada al contenido, podemos indicar respecto a las portadas que integran, al menos en los primeros seis números, un índice que si bien no es completo orienta los contenidos de cada revista. Además, el título que acompaña a cada revista se trata del texto central que puede ubicarse en las páginas 12 y 13 de cada edición. Sobre ciertos manifiestos que entrega Portal, estos pueden ubicarse principalmente en la sección de la Editorial, la que comenta entre otras cosas la misión y visión de la revista, los logros y las dificultades que tiene el proceso de publicación y mantención en vigencia de la misma. Sobre los temas y problemas contenidos en la revista, giran principalmente en torno a la posición de las letras chilenas en el escenario regional y global; la constante revisión crítica de las generaciones del 38, del 50 y la llamada "generación novísima" de la que participan contemporáneos como Enrique Lihn. Otros temas recurrentes están asociados a temáticas como Arte e Ideología, el compromiso del artista, y la escena artística nacional (considerando principalmente la música, el teatro y las letras). Los problemas que se acusan tienen que ver principalmente con la precariedad a la que se enfrenta el campo cultural de los sesenta en Chile, incluso en la Editorial del número 5 se acusan problemas económicos donde Portal debe enfrentar un panorama: 
cambiante de publicaciones que nacen y desaparecen. En esta misma página hacemos un acto de contrición, que constituye una evidente justificación de nuestra prolongada ausencia. Nuestra revista no recibe subvenciones. No pertenece a Institución, grupo o entidad de nombre confesable o confidencial. (Portal n ${ }^{\circ} 5$, p.5)

Este punto nos lleva directamente a hacer hincapié en la centralidad que comienza a jugar la Publicidad (presente desde el número 1 de Portal), que gana terreno en las páginas de la revista; esto debido principalmente a una necesidad de sanear las finanzas. Es así como desde la quinta edición los anuncios publicitarios vendrán por ejemplo a página completa, aumentando además numéricamente su presencia. Cabe indicar que la publicidad fue siempre variada, pasando desde concursos literarios, ediciones de libros, propaganda de galerías de arte; hasta anuncios de licores, grupos de estudios, electrónica, etc. En el mismo número de Portal, en un inserto llamado Así sale Portal (Portal n ${ }^{\circ}$, p.5) se hace alusión a una supuesta ida a la caja de empeños para poder continuar lanzando a la revista, dando cuenta de fuertes problemas económicos que podrían tener relación con el cese del uso del color en los números 6 y 7 .

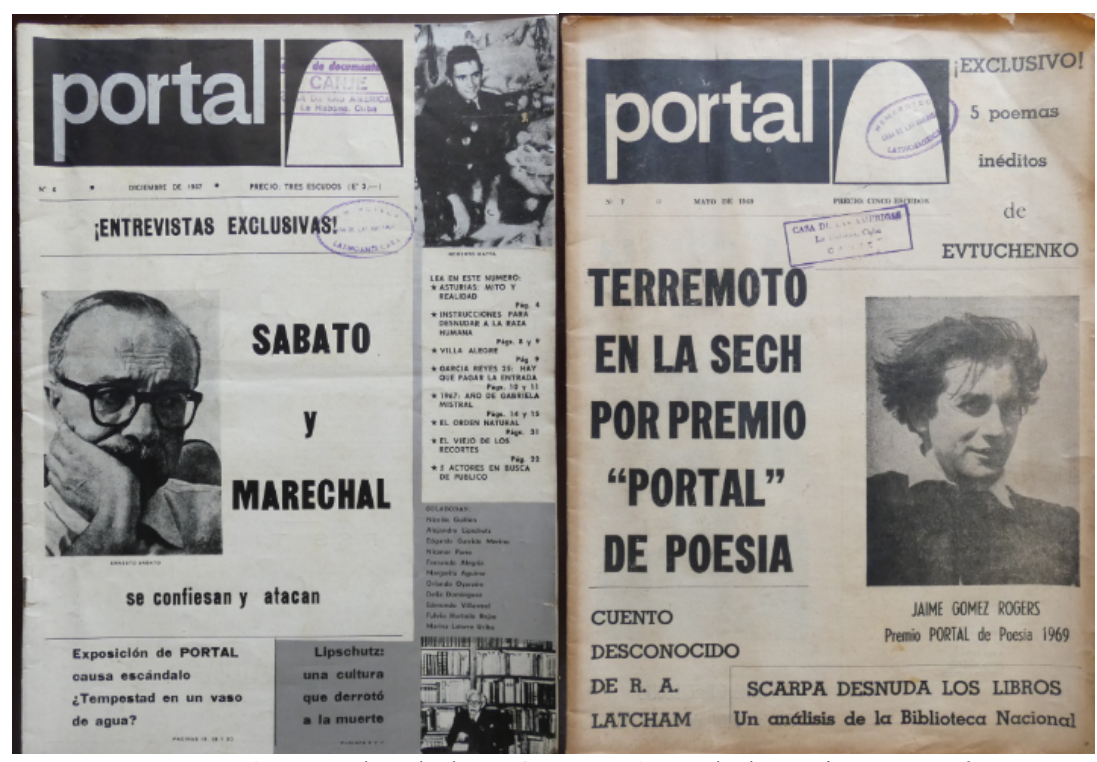

Imagen 4. Portadas de los números 6 y 7 de la revista Portal 


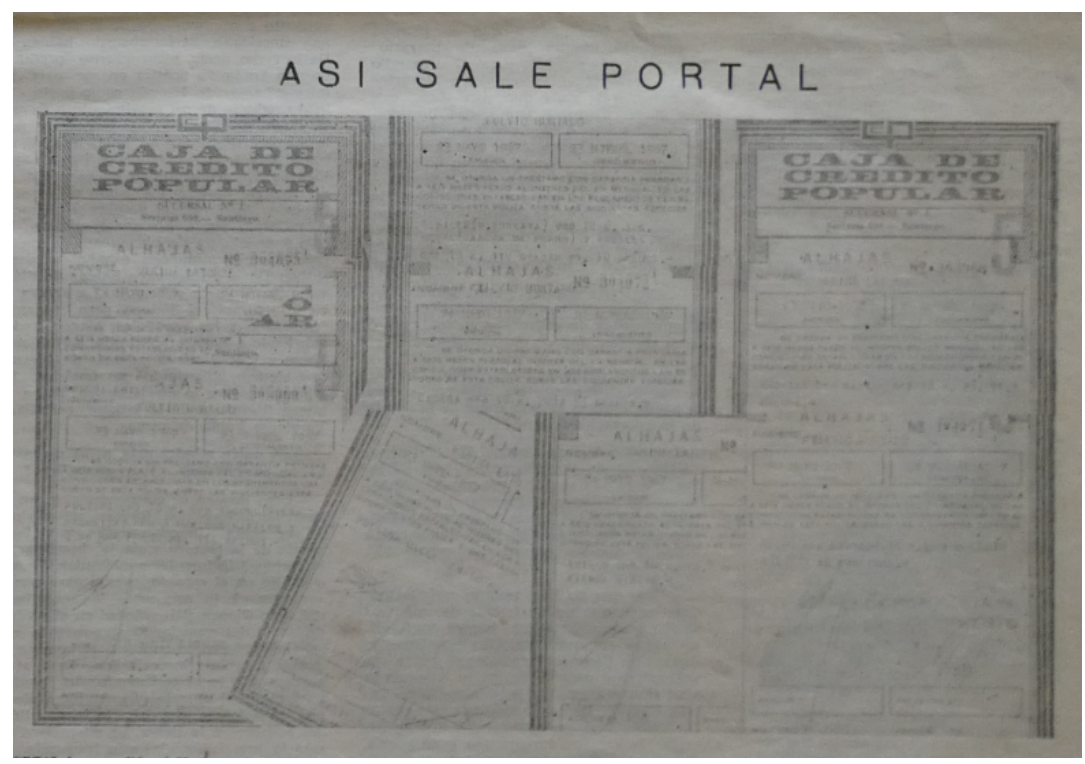

Imagen 5. "Así Sale Portal", revista Portal n5

\section{Lo latinoamericano: una disputa entre lo cultural y lo político}

Los debates y tensiones que podemos reconocer en la revista dan cuenta de un profundo interés por comprender el papel de las letras en la construcción de lo latinoamericano. Respecto a estas tensiones encontramos en el número 1 de Portal que data de diciembre de 1965, en una entrevista realizada al escritor Jorge Luis Borges (Portal $\left.n^{\circ} 1, p .20\right)$ donde se le pregunta sobre el futuro del capitalismo y su opinión respecto a la afirmación de que "Latinoamérica sería el continente del futuro"; Borges no dando mayor importancia a la primera pregunta, sobre Latinoamérica responde que "Si. Aquí hay fuerzas que no se han desarrollado y que inevitablemente crecerán. Por ahora tratamos de imitar a los europeos y no está mal que así sea. Pero en el futuro puede ocurrir al revés" (Portal n` 1, p.20). Respuesta que se puede interpretar como una visión que proyecta la posibilidad de un de ethos latinoamericano, que está aún supeditada a un predominante eurocentrismo cultural. De todas formas, Borges para estos años ya representaba una figura consagrada y por lo demás de la vieja escena de la literatura latinoamericana, lo que podría explicar una ligazón relacionada a su propia generación. En el mismo número se presenta una nota y entrevista sobre la compañía de teatro ICTUS, llamada "Pasión y Búsqueda", en la cual al preguntársele a Claudio Di Girolamo sobre el compromiso del artista, este responde que "si quiero cambiar la sociedad y construir (en el plano que me corresponde: el arte) una nueva ordenación, es indispensable que hoy mismo empiece un trabajo muy serio y consciente: cambiar y construir en mi interior un hombre nuevo, capaz de apasionarse por nuestro mundo, con lo bueno y lo malo que éste encierra" (Portal n ${ }^{\circ} 1$, p.19). En las palabras de Di Girolamo podemos observar una cierta influencia en torno -al menos- al concepto del hombre nuevo, de una tensión vivida por el artista de representar su tiempo, pero que no se ve empujado a salir de su campo de acción, dígase de paso que es el cultural y artístico. Cuestión que de todas formas se puede interpretar como un gesto político de corte más bien académico relacionado a la disciplina teatral. 
En el número 2 de Portal de junio de 1966, y en un artículo titulado "Jorge Teillier al revés y al derecho", donde se entrevista al poeta quién consultado sobre su arte considera que "la poesía me interesa no sólo como acto estético (la llamada poesía pura) si no ético. Una manera de cambiar el mundo, empezando por cambiarse a sí mismo, revelándose la imagen oculta y verdadera", a lo que agrega "por otra parte no basta criticar al mundo en que se vive, si no que presentar otro mejor". En la misma línea se le consulta sobre su postura frente a que un poeta comprometa su poesía con la política, a lo que responde "¿por qué no?, si la poesía es buena. Siempre que no haya subordinación no tanto a la política como a los políticos" (Portal n², p.4). Las respuestas de Teillier, sumada a la de otros artistas e intelectuales, comienzan a dar cuenta de cuestiones relativas al verdadero grado de interrelación o integración del arte y la cultura a la militancia en términos de absolutismo político, la cual presenta al menos para los últimos años de la década de los sesentas una distancia importante con las categorías del realismo socialista y por ende la supeditación del arte y el artista al proceso y al partido.

En esta misma edición, y retornando sobre la temática del Latinoamericanismo del periodo, resalta la crítica de arte encargada a César Cecci sobre la escena artística del año 1965 en Chile, quién considera como "uno de los momentos más importantes del año" la obra del músico peruano residente en Chile Celso Garrido Lecca, autor de Elegía a Machu Picchu, la que recibió además el premio como mejor obra del año por el instituto de Música de la Universidad de Chile.

Cecci dice respecto a la categoría que entrega de $<$ momento del año $>$, a que al decir momento "no quiere decir accidentalidad, transitoriedad ni pequeñez. [Si no que] quiere decir que, como siempre, el año 1965 se compuso de una sucesión de heterogeneidades, tanto en lo creativo como en lo interpretativo, y no de una organización de los programas con alguna identidad unitaria" (Portal ${ }^{\circ} 2$, p.16). Acontecimiento sobre el que podemos hacer diversas lecturas, donde sobresale el hecho que en Chile se haya entregado un premio chileno a un autor peruano, lo que demuestra cierta intención de integración latinoamericana, a lo que se suma el hecho simbólico de la temática de la pieza que tiene un cariz marcadamente regional en busca de una identidad latinoamericana incluso anterior al proceso de colonización.

Continuando con la revisión, en el número 3 de Portal de Julio de 1966 se publican dos entrevistas realizadas por María Elena Gartner. La primera se efectúa al joven danzarín chileno Fernando Cortizo, a quién se le pregunta dentro de cuál tendencia actual de la danza se ubica; a lo que responde que "reconozco proyección y dimensión de la danza sólo en Maurice Bejart y en Jerome Robbins. En cuanto a lo personal, siento la orfandad de una tendencia latinoamericana" (Portal, $\mathrm{n}^{\circ} 3, \mathrm{p} .16$ ). Continuando con el interrogatorio, Gartner le consulta sobre si la danza debe tener características propias latinoamericanas, a lo que responde que:

vivimos en medio de una geografía de belleza alucinante y agresiva, que ha producido danzas nacionales y regionales en cuyos ritmos, coloridos, instrumentos musicales, no sólo encontramos características propias, sino que esas características son de un valor y riqueza incalculable para una proyección escénica. Tenemos al alcance de la mano una herencia cultural propia de nuestro continente, y otra acabada y experimentada, que nos es ajena, como es la europea. Somos, además, exactamente lo contrario a lo que establecen los cánones de belleza física del hemisferio norte, y por lo tanto no deberíamos perdernos en formalismos que son incómodos a nuestra talla (temas, vestimentas, actitudes), que muchas veces nos hacen ver ridículos. En fin, tenemos todo para estar obligados a tener una danza con características propias. (Portal, ${ }^{\circ} 3$, p. 16) 
Podemos observar a modo de factor común en los diversos artistas e intelectuales la identificación de un periodo de acción, de un momento histórico de definiciones en torno al carácter regional de la cultura, las artes, y también el desarrollo en América Latina. Sin duda se presenta como revolucionario el ejercicio del quiebre estético, y la búsqueda de la síntesis productiva de lo "propio" como expresión de las formas culturales fuera del eje puramente europeo, representante del canon establecido. Continuando con la entrevista, Gartner le pregunta a Carrizo si le interesan los problemas políticos, a lo que este declara que "no pueden serme ajenos los problemas políticos, puesto que la detentación del poder, y su forma de dirigirlo hacia la masa, infieren directamente tanto en destinos de esa masa como del individuo" (Portal, $\mathrm{n}^{\circ} 3$, p.16). En la misma línea se le consulta sobre si el artista debe o no militar en un partido político o si puede ser fiel a una ideología sin militar, a lo que responde que cree que "el artista no debe militar en ningún partido político", agregando que "el hacerlo llevará en algún momento, al hombre, a un acto de traición, ya sea frente a su militancia o a su compromiso artístico", además que cree "que una obra de arte creada por un hombre de arraigadas convicciones ideológicas, reflejará de alguna manera esas tendencias, sin que en su concepción intervengan posiciones sectarias" (Portal, $\mathrm{n}^{\circ} 3, \mathrm{p} .16$ ). Nuevamente vemos, al igual que en la entrevista a Di Girólamo y Teillier, una diferenciación entre la política y la militancia de partido, marcado principalmente por el fantasma de la censura y la simbiosis entre el arte y el proceso revolucionario que afectó a los soviéticos, y que próximamente comenzaría a tener también sus manifestaciones en Cuba.

La otra entrevista realizada por Gartner al escritor Jaime Valdivieso, presenta posiciones opuestas a las de Cortizo, revelando una visión menos social y más individual del artista. Así, al preguntarle sobre su concepción del compromiso literario, este responde que lo entiende como "el estar profundamente comprometido con los temas y personajes que busco y escribo" (Portal, $\mathrm{n}^{\circ} 3$, p.17). Continuando con la entrevista, se le consulta igualmente sobre si un escritor debe participar activamente en política, a lo que responde que: "no creo que a un escritor deba exigírsele nada. Sólo debe exigírsele compromiso con su obra, y una profunda y auténtica vocación. Claro que si él desea y siente la necesidad de participar en política... ¡Bueno, que lo haga!". Cuestión que resulta problemática frente a la afirmación de Valdivieso, quién se declara como marxista. Pero uno que se califica "un marxista rebelde", ya que postula rebelarse "contra ciertas distorsiones e inconsecuencias en la aplicación concreta del marxismo en algunos países", agregando que

me duele, igualmente, lo que acaba de ocurrir en la Unión Soviética con los escritores. Además, creo que el marxismo no se ha desprendido aún, ni se ha hecho lo suficientemente para que se desprenda, de una ética bastante trasnochada. Falta que sea revolucionario en el campo de una moral más profunda, que abarque desde las ideas sobre el sexo, y el matrimonio, hasta las metafísicas. (Portal, n³, p.17)

Dejando patente una tensión clara entre la figura del artista como ente activo en términos sociales y políticos, y su adscripción a los cánones estéticos emanados de un deber ser. Estas dos entrevistas revelan lo que parece ser una constante en la revista, la multiplicidad de lecturas en torno al periodo entregadas por los artistas de la época. Que muestra una tendencia mayor a la identificación de un periodo histórico de compromiso político adscrito por los artistas más jóvenes, y una suerte de tedio sobre el tema representado en los artistas mayores. También deja de visto la tensión presente entre ser marxista, y la posición política e ideológica adoptada por estos respecto al rol del arte en el proceso político; cuestiones que se presentan en general 
separadas, o podemos decir que al menos pareciera ser una cuestión que Jaime Valdivieso -y posteriormente Carlos Maldonado- buscan separar.

Podemos encontrar una línea similar de diferenciación entre la adscripción a una ideología y la supeditación del artista a una estructura rígida de corte partidista en el número 4 de Portal (noviembre de 1966), donde en una entrevista al novelista chileno Edesio Alvarado se le interroga sobre el realismo, a lo que indica sobre el realismo de corte socialista que este puede producirle molestias "o al menos incomprensiones entre cierta gente de Izquierda auto limitada por su estatismo", a lo que agrega en tono expresivo:

¡Pero, qué diablos, soy marxista-leninista! Creo que el marxismo es la ideología creadora por excelencia. Por eso nada en ella entraba el acto de la creación estética, y debe estar ajena a formulaciones superadas o debilitadas por el enriquecimiento de la realidad y el mejor conocimiento de la naturaleza específica de los problemas espirituales. (Portal n4, pp.6-7)

Sobre lo que podrían considerarse los núcleos de irradiación política de <izquierda $>$ a nivel internacional y su recepción en Chile, y específicamente en el debate presentado en la revista, se reproducen pasajes de un foro efectuado por Portal donde se realizó cuestionamientos a cuatro poetas jóvenes chilenos. En un análisis de la pregunta realizada por el poeta Jorge Teillier, quién consultando a Alfredo Cortal (estudiante de periodismo de la Universidad de Chile, y que recibió el primer premio de poesía del año 1963) sobre a quién admira más: a un poeta, un cosmonauta, o un guerrillero; podemos observar una connotación positiva sobre estas figuras, pero llevadas al campo propio de la poesía o de lo que podríamos denominar el acto poético, más no en su componente sistémico ideológico, o al menos no se hace patente:

en el cosmonauta y en el guerrillero hay dos formas actualísimas de ser poeta. Un cosmonauta es el testimonio de la técnica y de la imaginación humanas hábilmente combinadas [...] pero si el cosmonauta es el testimonio del hombre proyectado al espacio, el guerrillero atestigua en dolorosa paradoja, la incomodidad del hombre en la tierra. El guerrillero denuncia una injusticia, una tremenda insatisfacción y usa las manos. (Portal n 5 , p.6-7)

Existe, por lo tanto, una presencia de lo soviético y del ejemplo de Cuba situados como lecturas del momento histórico, de hecho, si bien no es un tema central de la Revista Portal, la temática de lo soviético tiene bastante representación. Podemos citar en el número 5 la entrevista realizada por Portal al crítico de cine ruso Román Karmen de paso por Chile, donde participó como traductor Ignacio Stanislav de la empresa de difusión de cine soviético Soviexportfilm, en esta entrevista se toca el tema de la recepción del arte soviético en Chile con énfasis en el cine. Sobre esto, Karmen responde que "aquí se conoce una pequeña parte de la producción cinematográfica rusa. Tan pequeña, que no puede representar la extensa temática y estilos en todos sus variados matices. Con un lenguaje de vanguardia, puede utilizarse, indiferentemente, diversos lenguajes" (Portal n ${ }^{\circ}$, p. 19). Esta cita me parece que refleja una cuestión que se ha ido revelando a través del artículo, y que tiene que ver con la percepción en la época por los artistas e intelectuales que se dan revista en Portal, relacionado a una visión negativa de la relación generada en la Unión Soviética con la figura del artista, argumentándose en diversas ocasiones una fuerte crítica a las nociones del realismo soviético. Esta crítica, que aún no roza el polo 
cubano, pero hará crisis también hacia 1971 con el caso Padilla, tiene a los diversos colaboradores de Portal concentrados en no repetirla, cuestión que como se pudo observar Karmen entiende como un desconocimiento de las nuevas corrientes artísticas soviéticas que exploran nuevas temáticas. Incluso en los escritores que uno podría asociar al Partido Comunista como Teillier y Maldonado, y que podrían ser identificados a priori con en el esquema de dicotomía entre militantes y heterodoxos planteado por Zamorano (2016) para el periodo de la Unidad Popular, esta temática y precaución es central.

En un ejemplo centrado a una escala regional de la tensión entre los campos político y cultural, encontramos en la edición de diciembre de 1967 de Portal una nota titulada Matta vino a gritar: ¡Viva Cuba!, la que aborda una exposición realizada por Matta en Chile. A Matta se le describe como "un pintor chileno que ha hecho la mayor parte de su obra en el extranjero y se ha colocado entre los veinte mejor cotizados de la plástica mundial", que "vuelve a su tierra con un grito de combate, y a pintar murales en las escuelas, sindicatos y las calles", esto ya que "Matta es un artista vital y un ser humano comprometido con la causa de los pueblos atropellados. Militante de la causa de la paz, señaló claramente que "venía a gritar VIVA CUBA" (Portal nº, pp.16-17). Sobre la exposición abordada en el artículo, indica que esta se ha expuesto en importantes galerías del mundo, donde estos "omitieron los títulos que él dio a sus cuados, para ayudar a su amplia comprensión", cuestión que se puede enmarcar en el ambiente de Guerra Fría por el contenido político fundido en la estética del artista, produciendo títulos como Vivir enfrentando las flechas; los malditos encandiladores, y Agresión Imperialista a Vietnam, cuadros que sólo mantuvieron su nombre original en Cuba y Chile (Portal $n^{\circ} 6$, pp.16-17). La revista presenta algunas fotografías de cuadros de Matta, acompañados por reproducciones del libro de visitas que acompañó las exposiciones en la Galería Carmen Waugh y el Museo de Arte Contemporáneo, de las cuales resalta por la temática que aborda este articulo el comentario dejado por Marina Latorre Uribe, directora y dueña de Portal.

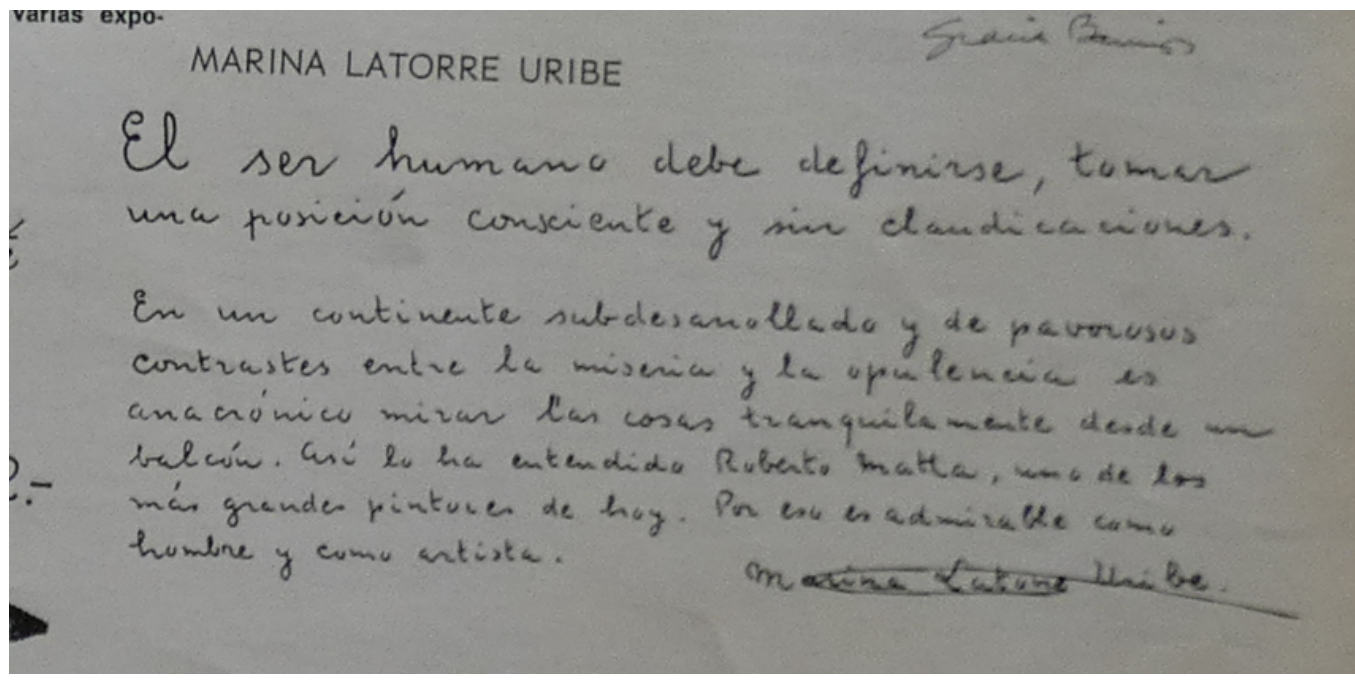

imagen 6. Comentario de Marina Latorre a Exposición de Matta. Portal $n^{\circ} 6$

En el comentario dejado por Marina Latorre, se comienzan a vislumbrar ciertos desplazamientos en la concepción general del campo artístico y cultural de la década de 1960. 
Así cuando en las primeras revistas no se entregaban definiciones tan comprometidas sobre la "labor" del artista, en este comentario Latorre resalta que

El ser humano debe definirse, tomar una posición consciente y sin claudicaciones. En un continente subdesarrollado y de pavorosos contrastes entre miseria y la opulencia es anacrónico mirar las cosas tranquilamente desde un balcón", a lo que continúa dirigiéndose a la figura de Matta por su afinidad con Cuba y la Revolución como "uno de los más grandes pintores de hoy. Por eso es admirable como hombre y como artista. (Portal $n^{\circ} 6, p .17$ )

En la línea de los debates entre arte y política, en un artículo firmado por Carlos Maldonado titulado "Arte e Ideología", este reflexiona en torno a esta tensión identificándola como "un viejo problema, pero que hoy hace crisis, especialmente por causa de una crítica que no quiere arrancarse las anteojeras de un obstinado sectarismo" (Portal n ${ }^{\circ}$, p.20). Para analizar esta tensión, va a echar mano al concepto de <condicionamiento social del arte> tomado de Karl Marx, indicando que si bien el arte está "condicionado socialmente" y entiende el intento de separar estos campos por parte de algunos artistas, determina que "el arte no puede estar totalmente marginado de las ideologías, [pero] debe entenderse como una "penetración" de éstas hacia aquél, mediante un proceso complejísimo y no de manera directa", entendiendo esta tensión como "la permanente lucha que el arte y la literatura ha mantenido en todas las épocas por escapar al tutelaje que ciertas clases o estratos sociales han tratado permanentemente de ejercer sobre ellos" (Portal $\mathrm{n}^{\circ} 7$, p.20). Maldonado identifica una suerte de madurez en el arte de temática universalista, el que al superar las limitaciones ideológicas de su clase social, logra trasuntar de manera general "las aspiraciones de su sociedad y de todos los hombres de su época", cuestión que de todas formas matiza, pues entiende que finalmente "la obra de arte no es sólo el espejo que registra el mundo objetivo, además es la pantalla en que se proyecta el mundo interior del hombre" (Portal $\mathrm{n}^{\circ} 7$, p.21), por lo que jamás el arte será aséptico de carga política o ideológica. Lo dicho por Maldonado viene a reafirmar una reflexión compartida por -al menos- los colaboradores de la Revista Portal, y que es el rechazo cuasi absoluto a la práctica doctrinaria asociada a la producción artística enmarcada en un realismo socialista de carácter soviético. Una reflexión producida desde la militancia o la afinidad tanto a los partidos en algunos casos, o al proceso histórico percibido en otros. La repetición de la problemática da a entender al menos la existencia de núcleos al interior del mundo de la política y la cultura que tensionan esta relación, en una actitud que se lee transversalmente como una ortodoxia basada en el ejemplo soviético, y que debe ser superada, pero sobre la cual no se identifican figuras y nadie parece adscribir abiertamente (al menos en los que colaboran en Portal).

De esta manera encontramos en Portal (1965-1969) una fuerte necesidad por identificar a las figuras literarias y artísticas del campo cultural latinoamericano, buscando a través de esto identificar ese "algo" latinoamericano, describiendo una suerte de quiebre estético en algunas áreas. Pero sobre todo, lo central en la revista pareciese ser lo relacionado a la necesidad de cambiar Latinoamérica a través del arte, identificando al arte mismo y al artista como un elemento en sí ya rupturista, revolucionario y denunciante; aunque con una noción de la búsqueda de algo propio y novedoso para abordar esta cualidad. De esta manera las claves de discusión en torno a lo latinoamericano estuvieron centradas principalmente en la posición que juegan los artistas e intelectuales en un proceso percibido como de cambios estructurales a nivel social y cultural, en un territorio donde resurgía una esperanza de conciliar arte y revolución de mano de 
la experiencia cubana, y en desmedro de la soviética. De esta manera, en la revista es posible encontrar la presencia de hitos como las alusiones a los premios Casa de las Américas, y también por sobre todo en ciertas señales que hablan de un cruce transfronterizo de los artistas, o al menos la existencia de una intensión por dar conocer la escena cultural latinoamericana; así como la conformación de ciertos espacios para este cometido, cuestión altamente valorada.

\section{Portal y su papel en la conformación del campo cultural chileno}

Sin duda alguna, y como hemos esbozado a través del artículo, la revista Portal a través de sus 7 números -correspondientes a la primera época de publicación-, busca por una parte reflejar la escena artística y cultural nacional, pero también en su calidad de proyecto editorial colectivo ligado a lo que entenderemos como un periodismo integral, va a ser un espacio de proposiciones de líneas de lectura y de producción artística. Por nombrar algunos de los aportes a la conformación de espacios artístico-culturales, podemos traer a colación la difusión incansable que realizó el grupo editorial por visibilizar las -descritas como desiertas- galerías de arte de Santiago; de esta manera se hacen diversas alusiones y propaganda a La Galería Central (Moneda 920), la Galería Patio o Patio Providencia (Providencia 1652) creada por Maruja Burchard y Lina Levine, galería que realizaba diversas exposiciones de artistas jóvenes y consagrados y que entregaba el premio Maruja Burchard.

No menos importante fue la labor de difusión que realizó con las diversas artes, cubriendo por ejemplo en el teatro a las compañías ICTUS, el ITUCH o el teatro TEKNOS; las tres de ámbito universitario. Portal también fue lumbrera de diversas iniciativas del mundo de la cultura, difundiendo -generalmente en modalidad de publicidad- diversas iniciativas de los institutos de Arte y de Extensión Musical de la Universidad de Chile. Mientras que en el ámbito de la literatura, cita en sus páginas a consagrados como Neruda, Coloane y Fernando Alegría; a la vez que daba espacio para presentar a las nuevas generaciones de las letras chilenas, o la llamada generación novísima del sesenta de la que participaba como figura sobresaliente Enrique Lihn. Sobre estas instancias, podemos nombrar el conflictuado premio Portal de Poesía, que más allá de la problemática por la participación de Mario Ferrero (quién era secretario de la SECH) como participante del concurso de Portal acusándose un conflicto de interés; la existencia de este premio nos da cuenta de la importancia de Portal como elemento reconocido y de peso entre la escena literaria, artística y cultural de Chile en los años sesenta ${ }^{9}$. De esta manera Portal en conjunción con otras instituciones de la época podía de cierta manera apoyar en reconocimiento y prensa a nuevas figuras, que en el caso del premio de 1969 recayó en Jaime Gómez Rogers de 28 años $^{10}$.

Otro hito importante son las diferentes obras literarias inéditas que se presentan a modo de primicias en Portal, de las que me gustaría visibilizar por su unicidad la Corbata Poética para Nicanor Parra, obra realizada personalmente por Pablo Neruda para el anti poeta que nunca llegó

9 Esta polémica generó fuertes críticas de Luis Sánchez Latorre "Filebo", reproducidas y ampliadas en la revista PEC (Escándalo poético, Portal nº, p.5).

${ }^{10}$ Jaime era estudiante de Castellano de la Universidad de Chile, y ayudante de cátedra. Autor de dos libros publicados a la fecha: "Diálogo para dos movimientos" y "La fuga de Sebastián y otros Poemas", que obtuvieron el premio Alerce. Su Obra "El Circo" ganó el premio Portal 1969. 
a sus manos, y que en una investigación realizada por Portal logra ser ubicada y conseguido los permisos para ser reproducida.

Como se indicó anteriormente, la Revista Portal fue dirigida por el matrimonio conformado por Eduardo Bolt Vega y Marina Latorre. Esta sociedad conyugal cuenta con una galería de arte: la Galería Bolt (Londres 92), ubicada en la misma dirección que la revista tiene su domicilio y oficinas de redacción. En esta galería se llevan a cabo diversas muestras y actividades de tipo cultural, entre las que podemos resaltar la conmemoración del aniversario de la muerte de Rubén Azócar realizado en 1966, o una exposición de artesanía peruana exhibida el mismo año y que contó con el auspicio y la organización de Portal y la Embajada del Perú, lo que demuestra los nexos institucionales de este núcleo de difusión y promoción cultural. Cuestión que se refuerza con los diversos atisbos indicados de crear un "club de amigos de Portal" que tendría una doble función: apoyar la existencia de la revista, y por otro lado dar cobertura mediática a las diversas expresiones de los artistas nacionales (Portal $\mathrm{n}^{\circ} 3, \mathrm{p} .5$ ). Un elemento que podría mostrarnos la posición que juega la revista Portal y la Editorial-Galería Bolt en el campo cultural de la década de los sesenta en Chile, tiene que ver con la polémica suscitada por la exposición Arte o Pornografía (1967), esta exposición generó las más diversas reacciones produciendo una "conmoción que sacudiría los círculos artísticos, que llegó -desde la iracunda- hasta ruborizantes elogios, pasando por todos los matices" (Portal $\left.n^{\circ} 6,18\right)$; reacción generada por 27 obras entre esculturas, grabados, pinturas, dibujos y collages que 14 artistas chilenos habían aportado a la muestra, la que rondaba en torno a la temática de El Amor como expresión del deseo que puede calificarse de erótico. Fueron expuestas esculturas de fierro de Sergio Castillo, pinturas orgánicas de Dámaso Ogaz, obras de Matta, Grumann, Luna, Garfias, Wexler, Lobos, Pohlhammer, Toral, García, Zeller, Mesa, Vásquez, Walker y Medge (Portal n6, 18). Pero más allá de la exposición en sí misma, lo que da cuenta de la centralidad o importancia de Portal en el campo cultural y artístico chileno es la reacción que genera en los demás periódicos y revistas que escriben -ya sea exclusivamente o no- de arte y cultura. Así por ejemplo encontramos ecos de esta exposición realizados por Pastor Aucapan en El siglo, Antonio Romera en El Mercurio, Antonio Avaria en La Nación, Raúl Mellado en El Siglo, Gaby Garfias en Las Ultimas Noticias, Juan Tejeda en La Nación, Carlos Ossa en El Siglo, Guillermo Bown en Última Hora, Corambe en El Siglo, Luciano Cruz en Flash, Francisco Otta en P.E.C., y Carlos Maldonado en El Siglo. Siendo estas opiniones sobre la exposición variadas, encontrando por ejemplo en las páginas del mismo periódico visiones contrariadas sobre la temática, leídas desde diversos puntos de vistas, cuestión que queda patente sobre todo en las diferentes valoraciones que hacen los escritores del El Siglo citados.

De esta manera hemos podido acercarnos a una aproximación desde la Revista Portal a la conformación de un campo artístico y cultural chileno en la década de los sesenta, un campo que está fuertemente tensionado por la creciente valoración de lo latinoamericano y que empuja a sus artistas y protagonistas a "comprometerse" con su época. Esta interrelación entre los campos político y cultural no va a ser exclusiva de Portal, sino que va a ser transversal a la época y la región. Cabe indicar que la posición adoptada o presentada desde las páginas de la publicación de Latorre y Bolt es siempre de mediación entre las artes y la cultura chilena y latinoamericana con la sociedad y el pueblo, en un ejercicio tanto productor como difusor de instancias culturales y artísticas, sobre una identificada demanda y necesidad por estos espacios. Finalmente me gustaría cerrar este artículo dando cuenta de un vacío historiográfico en torno a las diversas iniciativas en el ámbito de las artes y la cultura de la década de los sesenta, vacío que justifica -creo- la necesidad de estudiar estos procesos en la temporalidad escogida. Pues si bien la época de la 
Unidad Popular tiene cédulas suficientes para ser considerado un objeto de estudio en sí mismo, muchas de las discusiones y procesos se arrastran de la década pasada. De esta manera espero a futuro que los avances de esta investigación y otras que se realicen en esta área, iluminen este oscurecido momento de la historia cultural y política de Chile, aportando elementos para la discusión en torno a la construcción de la identidad artística latinoamericana de la época. Entregando así mayores y más certeras definiciones sobre las posiciones de los diversos artistas e intelectuales comprometidos con los procesos, los que parece mantuvieron una relación más bien alerta en torno a no repetir en Latinoamérica los vicios sufridos en otras latitudes en relación con el cruce problemático entre arte y política.

\section{Referencias bibliográficas}

Altamirano, C. (Dir.). (2010). Historia de los intelectuales en América Latina, Buenos Aires, Katz Editores, Vol. 1.

Beigel, F. (2003). Las revistas culturales como documentos de la historia latinoamericana. Revista Utopía y Praxis Latinoamericana (año 8, n²0), pp.105-115.

Berríos, P. (2011). Estrategias de inserción del arte latinoamericano. El internacionalismo en Jorge Romero Brest y el latinoamericanismo en Marta Traba. (Tesis para optar al grado de Magíster en Estudios Latinoamericanos). Universidad de Chile, Chile.

Bianchi, S. (1995). La Memoria: Modelo para armar. Grupos literarios de la década del sesenta en Chile. Chile, DIBAM.

Bourdieu, P. (2002). Campo de poder, campo intelectual, Buenos Aires-Argentina, Montressor

Canto Novoa, N. (2012). El lugar de la cultura en la vía chilena al socialismo. Notas sobre el proyecto estético de la Unidad Popular, Revista Pleyadé (n 9), pp. 153-178.

Dosse, F. (2012). De la historia de las ideas a la historia intelectual. Historia y grafia $\left(\mathrm{n}^{\circ} 19\right)$, México, pp. 171-192.

Ehrlicher, H. (2014). Introducción. En: Ehrlicher, H., Ribler-Pipka, N. (eds.) Almacenes de un tiempo en fuga: Revistas culturales en la modernidad hispánica. Berlín: Shaker Verlag.

Elizalde, L. (coord.). (2008). Revistas culturales latinoamericanas 1920-1960. México: Consejo nacional para la cultura y las artes, Dirección General de Publicaciones, Universidad Autónoma del Estado de Morelos, Universidad Iberoamericana.

Fornet, J. (2014). El 71. Anatomía de una crisis. Cuba: Letras Cubanas.

Gilman, C. (2003). Entre la pluma y el fusil. Debates y dilemas del escritor revolucionario en América Latina. Argentina: iglo XXI Editores.

. (2010). Casa de las Américas. Un esplendor en dos tiempos (1960-1971). En

Altamirano, C., (Dir.). (2010). Historia de los intelectuales en América Latina. Buenos Aires: Katz Editores, Vol. 1.

Gramsci, A. (2009). Los intelectuales y la organización de la cultura. Buenos Aires: Nueva Visión.

Longoni, A. (2004). Vanguardia y Revolución. Ideas y prácticas artístico-políticas en Argentina de los años 60/70, vol.1. (Tesis Doctoral), Facultad Filosofía y Letras UBA, Argentina. 
Lowy, M. (1997). Redención y utopía. El judaísmo libertario en Europa Central. Un estudio de afinidad electiva. Buenos Aires: Editorial El cielo por asalto.

Marchesi, M. (2010). Las redes culturales latinoamericanas y los debates del arte revolucionario (1970-1973). International Research Forum for Graduate Students and Emerging Scholars, University of Texas, Austin

Moraña, M. (2013). Revistas culturales y mediación letrada en América Latina. Travessia (40/ oitra travessia 1$)$.

Pita Gonzalez, A. (comp.). (2016): Redes Intelectuales transnacionales en América Latina durante la entreguerra. México: Editorial Miguel Ángel Porrúa, Universidad de Colima.

. (2014). Las revistas culturales como soportes materiales, prácticas sociales y espacios de sociabilidad. En Ehrlicher, H., Ribler-Pipka, N. (eds.). Almacenes de un tiempo en fuga: Revistas culturales en la modernidad hispánica. Berlín, Shaker Verlag.

Pita González A. y Grillo M. (2015). Una propuesta de análisis para el estudio de revistas culturales. RELMECS (Vol.5, $\left.\mathrm{n}^{\circ} 1\right)$.

Pluet-Despatin, J. (s.f). Contribución a la historia de los intelectuales, las Revistas. En AMÉRICALEE. El portal de publicaciones latinoamericanas del siglo XX. ISSN: 2545$823 \mathrm{X}$.

Rama, A (1998). La ciudad Letrada. Montevideo: Arca, 1998.

Revista Portal n 1-nº (1965-1969).

Sarlo, B. (1992). Intelectuales y revistas: razones de una práctica. América: Cahiers du CRICCAL (n॰9-10), pp. 9-16.

Zamorano Díaz, C. (2016). La revista Cormorán y su contribución al debate en torno a la cultura en la Unidad Popular. Izquierdas (n`30), pp. 215-235. 